\title{
Continuity of Primary Care and Emergency Hospital Admissions Among Older Patients in England
}

Peter Tammes, MA, $P b D^{1}$

Sarab Purdy, MBBS, MD, MPH

Cbris Salisbury, $M B C b B, M S c, M D^{1}$

Fiona MacKichan, MSc, $P b D^{1}$

Daniel Lasserson, $M A, M D^{2,3}$

Richard W. Morris, MSc, $P b D^{1}$

${ }^{1}$ Centre for Academic Primary Care, Bristol Medical School, University of Bristol,

Bristol, United Kingdom

${ }^{2}$ Nuffield Department of Medicine, University of Oxford, Oxford, United Kingdom

${ }^{3}$ Department of Gerontology, Oxford University Hospitals NHS Foundation Trust, John Radcliffe Hospital, Oxford, Oxford, United Kingdom

\section{$\sqrt{m}$ MORE ONLINE www.annfammed.org}

Conflicts of interest: authors report none.

\section{CORRESPONDING AUTHOR}

Peter Tammes, MA, PhD

Centre for Academic Primary Care Bristol Medical School

University of Bristol

Canynge Hall, 39 Whatley Rd

Bristol, BS8 2PS United Kingdom

p.tammes@bristol.ac.uk

\begin{abstract}
PURPOSE Secondary health care services have been under considerable pressure in England as attendance rates increase, resulting in longer waiting times and greater demands on staff. This study's aim was to examine the association between continuity of care and risk of emergency hospital admission among older adults.
\end{abstract}

METHODS We analyzed records from 10,000 patients aged 65 years and older in 2012 within 297 English general practices obtained from the Clinical Practice Research Datalink and linked with Hospital Episode Statistics. We used the Bice and Boxerman (BB) index and the appointed general practitioner index (last general practitioner consulted before hospitalization) to quantify patient-physician continuity. The BB index was used in a prospective cohort approach to assess impact of continuity on risk of admission. Both indices were used in a separate retrospective nested case-control approach to test the effect of changing physician on the odds of hospital admission in the following 30 days.

RESULTS In the prospective cohort analysis, the BB index showed a graded, nonsignificant inverse relationship of continuity of care with risk of emergency hospital admission, although the hazard ratio for patients experiencing least continuity was $2.27(95 \% \mathrm{Cl}, 1.37-3.76)$ compared with those having complete continuity. In the retrospective nested case-control analysis, we found a graded inverse relationship between continuity of care and emergency hospital admission for both $\mathrm{BB}$ and appointed general practitioner indices: for the latter, the odds ratio for those experiencing least continuity was $2.32(95 \% \mathrm{Cl}, 1.48-3.63)$ relative to those experiencing most continuity.

CONCLUSIONS Marked discontinuity of care might contribute to increased unplanned hospital admissions among patients aged 65 years and older. Schemes to enhance continuity of care have the potential to reduce hospital admissions.

Ann Fam Med 2017;15:515-522. https://doi.org/10.1370/afm.2136.

\section{INTRODUCTION}

A cute hospital services in England have been under increasing pressure. Evidence suggests that many patients presenting for unscheduled secondary care could be managed in primary care. ${ }^{1,2}$ Aspects of general practice therefore might be associated with emergency department attendance and unplanned hospital admission.

Two systematic reviews have concluded that better clinician continuity of care (seeing the same clinician over time) reduces hospitalization. ${ }^{3,4}$ Recent analyses of the Taiwanese Longitudinal health Insurance Database produced similar findings. ${ }^{5-7}$

Studies investigating the impact of continuity of care using individualpatient UK data for acute presentations are scarce, however. Salisbury et $\mathrm{a}^{8}$ focused on multimorbidity and continuity of care, while Ridd et $\mathrm{al}^{9}$ focused on continuity and diagnosis of cancer, but neither included acute care. Barker et $\mathrm{a}^{10}$ found an association between higher continuity of care and fewer admissions for ambulatory care-sensitive conditions. 
Other UK-based studies have used information from the General Practitioner Patient Survey, providing information at the practice level such as the proportion of patients able to consult their preferred general practitioner. ${ }^{11-15}$ These ecological studies differ in their findings regarding the impact of continuity of care on (unplanned) hospital admission, however.

In the United Kingdom, patients are registered at one general practice but might see different physicians within that practice. On the basis of the assumption that the general practitioner regularly seen by the patient knows that patient well, we hypothesized that better continuity of care specifically with that physician would be associated with a lower risk of emergency hospital admission at the individual patient level. We focused on older adults as they are seen more frequently in primary care than younger adults ${ }^{16}$ and are at greater risk for acute hospital admission. ${ }^{17}$

\section{METHODS}

\section{Study Design and Setting}

We obtained data from the Clinical Practice Research Datalink (CPRD), which contains current data on 4.4 million anonymized patients $(6.9 \%$ of the UK population) and is nationally representative in terms of age, sex, and ethnicity. ${ }^{18}$ A practice-level deprivation score, Index of Multiple Deprivation 2010 quintile, was calculated after practice postcodes were mapped to geographic regions termed lower-layer super output areas, and practices were categorized as conurbation, urban, or rural. Staff roles of the clinician at each consultation were recorded, and data were obtained on each patient's date of consultations, sex, and year of birth. ${ }^{18}$ The CPRD can be linked with Hospital Episode Statistics and Office for National Statistics mortality data in England ${ }^{19}$ and we studied patients in CPRD who could be linked by their National Health Service number to Hospital Episode Statistics data, which showed emergency hospital admissions in the fiscal years 2012-2014.

We drew a random sample of 10,000 patients aged 65 years and older in 2012 within 297 English practices from all patients in the CPRD source population, stratified by general practitioner practice, and also sampling so that the proportions of patients in each practice in the sample matched the proportions among eligible patients. When undertaking this study, previous evidence for the effect of continuity of care ${ }^{4}$ consisted of 4 relevant studies: the only one using individual data among older adults reported an odds ratio of 0.67 for ambulatory care-sensitive hospitalizations. ${ }^{20}$ We had anticipated an emergency admission incidence of 125 per 1,000: when dividing patients equally into "highcontinuity" and "low-continuity" groups, an odds ratio of 0.67 would be detectable with $90 \%$ power at the $P=.05$ level with only 3,000 patients. As other evidence $^{4}$ suggested that this effect size was optimistic, we selected 10,000 patients (the maximum possible given the project budget), which allowed $90 \%$ power to detect a risk ratio of 0.83 (approximately one-half the effect size initially estimated).

We tested our hypothesis using 2 approaches: a prospective cohort approach to assess the general impact of continuity of care on emergency admissions and a nested case-control approach to assess whether seeing general practitioners other than the usual one increases the risk or odds of emergency admission during the following 30 days.

\section{Prospective Cohort Approach}

For the prospective cohort approach, the observation period for patients' general practitioner consultation history ran from April 1, 2010, to March 30, 2014, or earlier if patients left their current practice, for example, moving or dying (censored observation), or if they were admitted to the hospital between April 2012 and March 2014. Patients were selected if they made at least 2 general practitioner consultations after March 2012; in total 8,248 patients in our sample were included in the prospective cohort analysis. The observation period during which those patients were at risk for an emergency hospital admission started on the date of the second general practitioner consultation after March 2012 and ended on March 30, 2014, or earlier if they left the practice (Supplementary Figure 1, http://www.annfammed.org/content/15/6/515/ suppl/DC1). In total, 1,828 of the 8,248 patients had an emergency hospital admission within that time period.

\section{Nested Case-Control Approach}

For the nested case-control approach, we identified patients with an emergency hospital admission between April 1, 2012, and March 30, 2014. Patients were included as cases only if they had at least 2 general practitioner consultations in the 2 years before hospital admission, of which the last was within 30 days before that admission (Supplementary Figure 2, http://www.annfammed.org/content/15/6/515/suppl/ DC1). We chose a period of 30 days to capture a time span over which the general practitioner's care might affect the chance of an emergency admission. In total, 1,215 patients were selected as potential case patients. Control patients were defined as those not experiencing an emergency hospital admission, and were matched with case patients on the following characteristics: general practitioner practice, age-group, and occurrence of last general practitioner consultation 30 days before hospitalization of the matched case 
patient, with at least 1 other consultation made in the previous 2 years. We did not limit the number of controls per case. In total, 769 (63.3\%) of the case patients could be matched, and 2,123 patients qualified to be control patients (Supplementary Figure 3, http://www. annfammed.org/content/15/6/515/suppl/DC1).

\section{Outcome Measure}

Our main outcome measure was the first emergency hospital admission between April 2012 and March 2014. We did not make any distinction between admissions by specific routes, that is, admission through the emergency department or admission via direct general practitioner referral to a hospital specialty.

\section{Measures of Continuity of Care}

We measured longitudinal continuity of care (consultations over time with as few different doctors as possible). ${ }^{21}$ Practice staff identified as senior partners, partners, or salaried partners were classified as general practitioners. Labels such as associate and assistant, which might or might not indicate a general practitioner, made up very few consultations (each less than $0.4 \%$ ) and were excluded. Locum consultations were also excluded as numbers were small (approximately $2 \%)$. Consultation locations included clinics, home visits, out-of-hours visits, telephone consultations, and third-party consultations; multiple consultations occurring on the same day for an individual patient were counted as separate consultations.

We used 2 indices to measure longitudinal continuity of care: one that requires an assigned clinician and one that does not. ${ }^{22}$ The Bice and Boxerman (BB) index ${ }^{23}$ which does not need an assigned general practitioner, is also known as the Continuity of Care index. We divided $\mathrm{BB}$ index scores into 6 categories; patients with a score of 0 (complete absence of continuity of care) and of 1 (complete continuity of care), and 4 quartiles of those with scores falling between 0 and 1 . In a sensitivity analysis, the BB index score was divided into tertiles, not separating patients with scores of 0 and of $1 .{ }^{24}$ The provider identification index ${ }^{25}$ (see Supplementary Textbox 1, http://www.annfammed.org/content/15/6/515/suppl/DC1) requires an assigned clinician. The score for this index, which we termed appointed general practitioner index, is the proportion of visits during the study period to the general practitioner most recently visited before the index event of hospitalization for the case patients; we divided scores into quartiles.

\section{Measures of Confounding Variables}

Our choice of confounding variables was guided by the QAdmissions score, ${ }^{26}$ previously developed using data from a similar routine general practitioner data- base to predict hospital admissions. We included age, sex, number of general practitioner consultations, and having had a previous emergency hospital admission in 2010-2012. We also included the following morbidities measured before April 2012 (presence of each diagnosis was ascertained using published clinical code lists as collected in the Manchester Clinical Codes repository $^{27}$ ): epilepsy, ${ }^{28}$ chronic renal disease, ${ }^{29}$ cancer, ${ }^{30}$ asthma ${ }^{29}$ stroke $^{31}$ coronary heart disease, ${ }^{31}$ diabetes, ${ }^{31}$ chronic obstructive pulmonary disease, ${ }^{28}$ depression, ${ }^{32}$ and schizophrenia. ${ }^{32}$ Furthermore, we took into account clustering at the practice level ${ }^{33}$ : we included practice-level information including deprivation, location (conurbation, urban, rural), and estimated the number of general practitioners in a practice ascertained from consultations and staff role information.

\section{Statistical Methods}

In the prospective cohort analysis, we applied mixedeffects Weibull regression analysis to model the relative hazard of the first emergency admission in relation to the level of continuity of care a patient experienced during follow-up, adjusting for the clustering due to the different practices wherein patients were registered. In the retrospective nested case-control analysis, we applied conditional logistic regression analysis to obtain odds ratios for having had an emergency hospital admission in relation to the level of continuity of care a patient experienced.

\section{RESULTS}

\section{Prospective Cohort Analysis}

Figure 1 shows that the distribution of BB index scores varied widely among the 8,248 patients in the prospective cohort analysis. Overall, 95 (1.1\%) and 575 (6.9\%) of patients never and always, respectively, saw the same general practitioner when visiting that physician's practice, corresponding to continuity of care scores of 0 and 1 . As these patients consulted a general practitioner less frequently (Supplementary Table 1, http:// www.annfammed.org/content/15/6/515/suppl/DC1), we adjusted for the number of general practitioner consultations in analyses.

Table 1 shows the results of the mixed-effects Weibull regression model for unadjusted and adjusted associations between patients' BB index score and risk of emergency hospital admission. In the unadjusted model, patients with less than perfect continuity of care (BB index score $<1$ ) experienced a higher incidence of emergency hospital admission. A similar pattern was seen after adjustment, although the higher incidence was statistically significant only for those with a $\mathrm{BB}$ index score of 0 . When examining the trend 
across the 6 categories of scores $(1=$ highest, $6=$ lowest) as discrete categories, the hazard ratio per each

\section{Figure 1. Distribution of Bice and Boxerman index scores among the 8,248 patients in the prospective cohort analysis.}

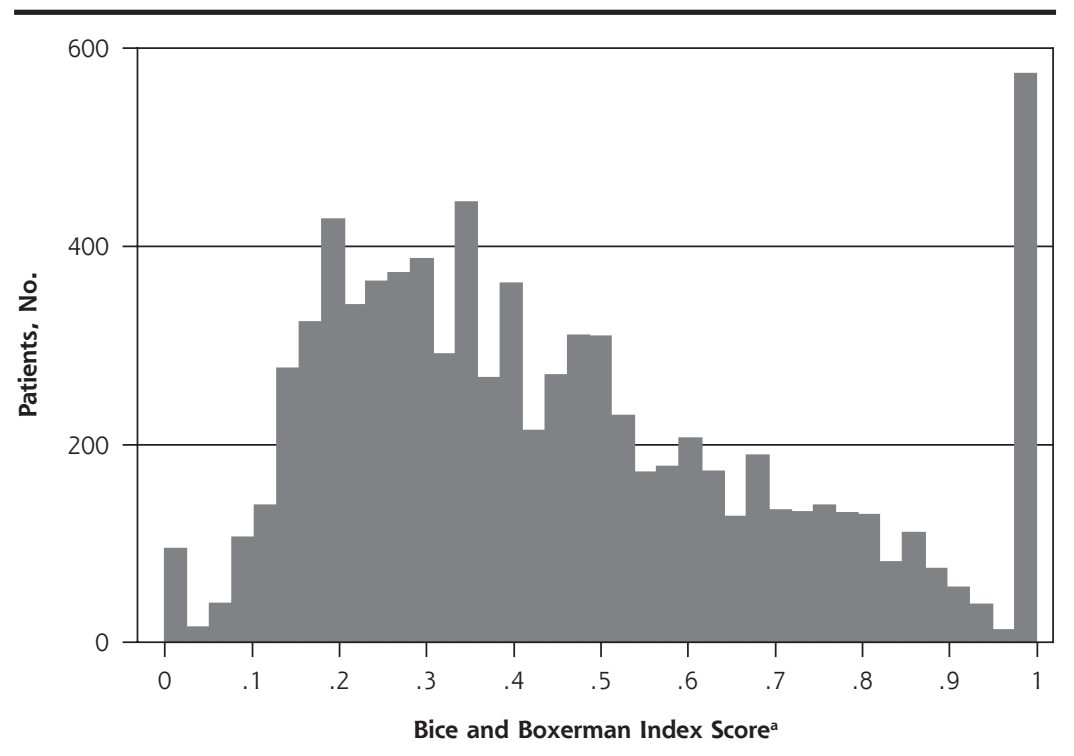

a Higher score indicates greater continuity of care.

Table 1. Association Between BB Index Score and Risk of Emergency Hospital Admission in the Prospective Cohort Analysis $(N=8,248)$

\begin{tabular}{|c|c|c|c|c|c|}
\hline \multirow[b]{2}{*}{ BB Index Score } & \multirow[b]{2}{*}{$\begin{array}{l}\text { Patients, } \\
\text { No. }\end{array}$} & \multicolumn{2}{|c|}{ Unadjusted } & \multicolumn{2}{|c|}{ Adjusted $^{a}$} \\
\hline & & $\begin{array}{c}\text { Hazard Ratio } \\
(95 \% \mathrm{Cl})\end{array}$ & $\begin{array}{c}P \\
\text { Value }\end{array}$ & $\begin{array}{c}\text { Hazard Ratio } \\
(95 \% \mathrm{Cl})\end{array}$ & $\begin{array}{c}P \\
\text { Value }\end{array}$ \\
\hline \multicolumn{6}{|l|}{ Of the patient } \\
\hline 0 & 95 & $\begin{array}{c}1.589 \\
(0.970-2.604)\end{array}$ & .07 & $\begin{array}{c}2.272 \\
(1.371-3.764)\end{array}$ & .001 \\
\hline Q1 $(>0$ to $<0.247)$ & 1,892 & $\begin{array}{c}1.188 \\
(0.953-1.482)\end{array}$ & .13 & $\begin{array}{c}1.123 \\
(0.882-1.431)\end{array}$ & .35 \\
\hline $\mathrm{Q} 2(0.247$ to $<0.383)$ & 1,891 & $\begin{array}{c}1.091 \\
(0.875-1.358)\end{array}$ & .44 & $\begin{array}{c}1.050 \\
(0.830-1.329)\end{array}$ & .69 \\
\hline Q3 $(0.383$ to $<0.567)$ & 1,901 & $\begin{array}{c}1.101 \\
(0.885-1.369)\end{array}$ & .39 & $\begin{array}{c}1.053 \\
(0.837-1.323)\end{array}$ & .66 \\
\hline $\mathrm{Q} 4(0.567$ to $<1)$ & 1,894 & $\begin{array}{c}1.031 \\
(0.829-1.281)\end{array}$ & .78 & $\begin{array}{c}0.963 \\
(0.768-1.206)\end{array}$ & .74 \\
\hline 1 (ref) & 575 & 1.000 & - & 1.000 & - \\
\hline \multicolumn{6}{|l|}{ Of the practice, average } \\
\hline $\mathrm{Q} 1(<0.336)$ & 2,085 & $\begin{array}{c}1.083 \\
(0.915-1.282)\end{array}$ & .35 & $\begin{array}{c}0.968 \\
(0.809-1.158)\end{array}$ & .70 \\
\hline $\mathrm{Q} 2(0.366$ to $<0.436)$ & 2,017 & $\begin{array}{c}0.916 \\
(0.771-1.089)\end{array}$ & .32 & $\begin{array}{c}0.853 \\
(0.718-1.014)\end{array}$ & .07 \\
\hline Q3 $(0.436$ to $<0.535)$ & 2,068 & $\begin{array}{c}0.871 \\
(0.735-1.031)\end{array}$ & .11 & $\begin{array}{c}0.878 \\
(0.744-1.037)\end{array}$ & .12 \\
\hline Q4 (0.535) (ref) & 2,078 & 1.000 & - & 1.000 & - \\
\hline \multicolumn{6}{|c|}{$\mathrm{BB}=$ Bice and Boxerman; $\mathrm{Q}=$ quartile ref $=$ reference category . } \\
\hline \multicolumn{6}{|c|}{ Note: Estimated hazard ratios are from mixed-effects Weibull regression analysis. } \\
\hline \multicolumn{6}{|c|}{$\begin{array}{l}\text { adjusted for age, sex, number of general practitioner consultations, having had a previous emergency hospital } \\
\text { admission in 2010-2012, deprivation level, general practitioner practice location (urban/rural), number of gen- } \\
\text { eral practitioners in a practice, and the following morbidities: diabetes, chronic obstructive pulmonary disease, } \\
\text { asthma, epilepsy, cancer, stroke, coronary heart disease, chronic renal disease, depression and schizophrenia. For } \\
\text { the complete table, see Supplemental Table } 2 \text { (http://www.annfammed.org/content/15/6/515/suppl/DC1). }\end{array}$} \\
\hline
\end{tabular}

increasing category was 1.042 (95\% CI, 0.997-1.090; $P=.07)$. The practice average $B B$ index score was not associated with a patient's risk of an emergency hospital admission in either the unadjusted models or the adjusted models.

A sensitivity analysis with $\mathrm{BB}$ index scores divided into tertiles showed no significant association (Supplementary Table 3, http://www.annfammed.org/ content/15/6/515/suppl/DC1).

\section{Nested Case-Control Analysis BB Index}

Scores on the $\mathrm{BB}$ index varied widely among the 2,892 patients in the retrospective nested casecontrol analysis (Supplementary Figure 4, http://www.annfammed. org/content/15/6/515/suppl/

DC1). Almost 300 (9.8\%) of the patients always saw the same general practitioner when visiting the practice, corresponding to a score of 1. Again, patients with a BB index score of 0 or 1 consulted a general practitioner less frequently (Supplementary Table 4, http://www.annfammed.org/ content/15/6/515/supp1/DC1).

Table 2 shows the results of the conditional regression model for unadjusted and adjusted associations between the BB index score and risk of emergency hospital admission. In the unadjusted model, there was an association between less than perfect continuity of care and higher odds of emergency hospital admission. A similar result was seen in the adjusted model, particularly showing higher odds among those with an index score of less than 0.4. When analyzing the $6 \mathrm{BB}$ index score categories as discrete scores $(1=$ highest, $6=$ lowest $)$, the associated odds ratio per each increase in category was 1.162 (95\% CI, 1.067-1.265; $P=.001$ ).

A sensitivity analysis with $\mathrm{BB}$ index scores divided into tertiles showed that patients whose 
Table 2. Association Between BB Index Score and Odds of Emergency Hospital Admission in the Nested Case-Control Analysis ( $\mathrm{N}=2,892)$

\begin{tabular}{|c|c|c|c|c|c|c|c|c|}
\hline \multirow[b]{2}{*}{ BB Index Score } & \multirow{2}{*}{$\begin{array}{c}\text { Case } \\
\text { Patients, } \\
\text { No. }\end{array}$} & \multirow{2}{*}{$\begin{array}{c}\text { Control } \\
\text { Patients, } \\
\text { No. }\end{array}$} & \multicolumn{3}{|c|}{ Unadjusted } & \multicolumn{3}{|c|}{ Adjusted $^{a}$} \\
\hline & & & Odds Ratio & $95 \% \mathrm{Cl}$ & $P$ Value & Odds Ratio & $95 \% \mathrm{Cl}$ & $P$ Value \\
\hline 0 & 14 & 60 & 1.525 & $0.752-3.094$ & .24 & 2.148 & $1.009-4.572$ & .047 \\
\hline $\mathrm{Q} 1(>0$ to $<0.257)$ & 188 & 446 & 2.674 & $1.762-4.059$ & $<.001$ & 1.832 & $1.157-2.901$ & .01 \\
\hline Q2 $(0.257$ to $<0.395)$ & 171 & 437 & 2.137 & $1.422-3.212$ & $<.001$ & 1.569 & $1.002-2.427$ & .049 \\
\hline Q3 $(0.395$ to $<0.576)$ & 176 & 486 & 1.989 & $1.331-2.973$ & .001 & 1.370 & $0.881-2.130$ & .16 \\
\hline $\mathrm{Q} 4(0.576$ to $<1)$ & 171 & 459 & 1.935 & $1.307-2.866$ & .001 & 1.170 & $0.758-1.807$ & .48 \\
\hline 1 (ref) & 49 & 235 & 1.000 & & - & 1.000 & & - \\
\hline
\end{tabular}

$\mathrm{BB}=$ Bice and Boxerman; $\mathrm{Q}=$ quartile; ref = reference category.

Note: Estimated odds ratios from a conditional (fixed-effects) logistic regression analysis.

a Adjusted for sex, number of general practitioner consultations, previous hospital admission, and morbidities. For complete table, see Supplemental Table 5, http:// www.annfammed.org/content/15/6/515/suppl/DC1.

scores were in the low and middle tertiles had odds ratios of $1.589(95 \% \mathrm{CI}, 1.212-2.084 ; P=.001)$ and $1.304(95 \% \mathrm{CI}, 1.013-1.678 ; P=.04)$, respectively, when compared with counterparts whose index scores were in the high tertile (highest continuity), showing a gradient of increasing risk of emergency hospital admission (Supplementary Table 6, http://www.annfammed. org/content/15/6/515/suppl/DC1).

\section{Appointed General Practitioner Index}

Figure 2 shows that the distribution of the appointed general practitioner index scores also varied widely among patients included in the nested case-control analysis. Again, almost 300 patients always saw their

\section{Figure 2. Distribution of appointed general practitioner index scores among the 2,892 patients in the nested case-control analysis.}

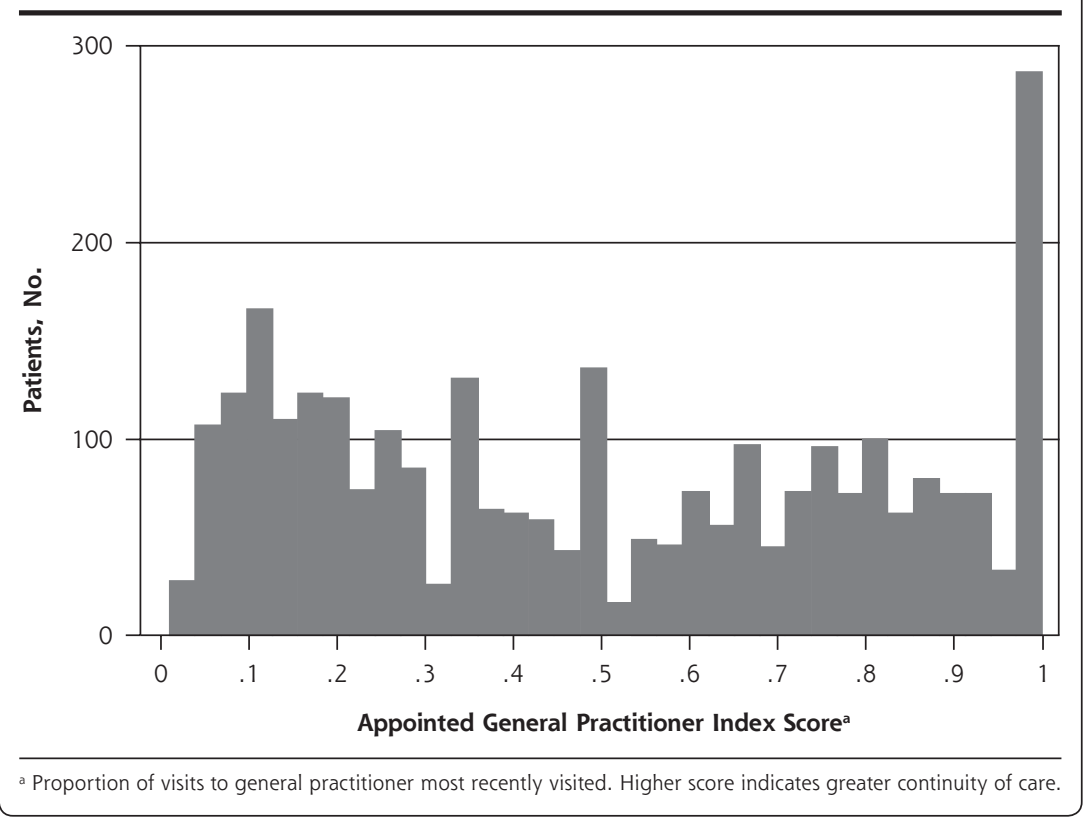

appointed general practitioner (before admission or at the respective time point for control patients) when visiting the practice, corresponding to a score of 1 . Patients with a low (first-quartile) index score had consulted a general practitioner more often (Table 3). In the analysis, we therefore adjusted for number of general practitioner consultations.

Table 4 shows the results of the conditional regression model for unadjusted and adjusted associations between the appointed general practitioner index score and odds of emergency hospital admission. The odds ratios for emergency hospital admission were higher for patients who did not see their appointed general practitioner every time they consulted the practice.

This association was especially marked for those who saw their appointed general practitioner fewer than 4 out of 10 times in the adjusted model. When regarding the 5 categories of general practitioner index score as discrete categories ( 1 = highest, $5=$ lowest $)$, the associated odds ratio per each increase in category was 1.266 (95\% CI, 1.161$\left.1.372{ }_{i} P<.001\right)$.

\section{DISCUSSION}

\section{Principal Findings}

Our results show that older patients who experienced more discontinuity of care in general practice had a higher risk of an emergency hospital admission. Within the nested case-control analysis, patients who had lower 


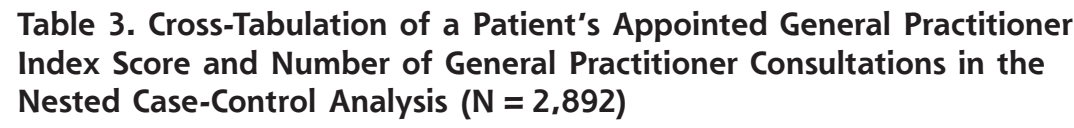

\begin{tabular}{lccccc}
\hline $\begin{array}{l}\text { General } \\
\text { Practitioner }\end{array}$ & \multicolumn{4}{c}{ General Practitioner Consultations, No. (\%) } & \\
\cline { 2 - 5 } Index Score & \multicolumn{1}{c}{$\mathbf{2 - 7}$} & $\mathbf{8 - 1 2}$ & $\mathbf{1 3 - 1 9}$ & $\mathbf{2 0}$ & Total \\
\hline Q1 $(0.01$ to $<0.18)$ & $77(12.1)$ & $157(24.7)$ & $167(26.3)$ & $234(36.9)$ & $635(100.0)$ \\
Q2 $(0.18$ to $<0.40)$ & $188(28.1)$ & $174(26.0)$ & $150(22.4)$ & $157(24.5)$ & $669(100.0)$ \\
Q3 $(0.40$ to $<0.71)$ & $175(27.1)$ & $153(23.7)$ & $159(24.7)$ & $158(24.5)$ & $645(100.0)$ \\
Q4 $(>0.71$ to $<1)$ & $96(14.6)$ & $170(25.8)$ & $168(25.5)$ & $225(34.1)$ & $659(100.0)$ \\
1 & $151(53.7)$ & $61(21.5)$ & $51(18.0)$ & $21(7.4)$ & $284(100.0)$ \\
Total & $687(23.8)$ & $715(24.7)$ & $695(24.0)$ & $795(27.5)$ & $2,892(100.0)$ \\
\hline
\end{tabular}

$\mathrm{Q}=$ quartile

continuity of care in general practice, whether assessed with the BB index score or the appointed general practitioner index score, had significantly higher odds of this adverse outcome. Additionally, results obtained using the appointed general practitioner index suggest that an encounter with a general practitioner other than the appointed one was associated with increased risk of admission within 30 days. In the prospective cohort analysis and using the BB index score, the trend was in the same direction, although only patients with a score of 0 had a significantly higher risk of emergency hospital admission.

\section{Strengths and Limitations}

Within the United Kingdom, patients are registered at a single general practice but may see different physicians within that practice; therefore, this setting is ideal for studying the impact of continuity of care at the individual patient level. Our study used longitudinal individual-level data from older patients in the CPRD to assess continuity of care and its relationship with the incidence of unplanned admission, filling a methodologic gap. ${ }^{34}$ We computed 2 commonly used types of longitudinal continuity of care measures for patients who had consulted a general practitioner at least twice: the BB index score and the appointed general practitioner index score (in this study taken to be the last general practitioner seen before admission). Both indices showed high frequencies of 0 (worst possible continuity) and 1 (best possible continuity), partly attributable to low numbers of consultations by these patients, so we accordingly defined them as separate categories. We repeated analysis, instead dividing the whole distribution of scores by tertiles (Supplementary Tables 3 and 6), but saw essentially similar trends. By selecting the most recent general practitioner seen before hospitalization within the nested case-control analysis, we could have introduced potential for confounding by indication, as seeing a general practitioner other than the usual one may indicate need for an urgent examination because of clinical deterioration rather than being causal. Furthermore, a longer observation period might have increased the number of patients with sufficient consultations to estimate continuity of care, and might have reduced the number of patients having perfect continuity of care.

An advantage of this database, however, was that it allowed us to apply 2 study designs: a prospective cohort approach and a nested case-control approach. For this study, the nested case-control approach might be more appropriate for testing the impact of continuity of care on emergency hospitalization as the last consultation with the general practitioner was within 30 days of hospital admission. Furthermore, within the nested case-control analysis, we matched patients on

Table 4. Association Between Appointed General Practitioner Index Score and Odds of Emergency Hospital Admission in the Nested Case-Control Analysis $(\mathrm{N}=2,892)$

\begin{tabular}{|c|c|c|c|c|c|c|c|c|}
\hline \multirow{2}{*}{$\begin{array}{l}\text { General } \\
\text { Practitioner } \\
\text { Index Score }\end{array}$} & \multirow{2}{*}{$\begin{array}{c}\text { Case } \\
\text { Patients, } \\
\text { No. }\end{array}$} & \multirow{2}{*}{$\begin{array}{c}\text { Control } \\
\text { Patients, } \\
\text { No. }\end{array}$} & \multicolumn{3}{|c|}{ Unadjusted } & \multicolumn{3}{|c|}{ Adjusted $^{a}$} \\
\hline & & & Odds Ratio & $95 \% \mathrm{Cl}$ & $P$ Value & Odds Ratio & $95 \% \mathrm{Cl}$ & $P$ Value \\
\hline Q1 (0.01 to <0.18) & 232 & 403 & 3.591 & $2.393-5.387$ & $<.001$ & 2.318 & $1.481-3.627$ & $<.001$ \\
\hline Q2 $(0.18$ to $<0.40)$ & 177 & 492 & 2.096 & $1.391-3.157$ & $<.001$ & 1.614 & $1.033-2.522$ & .04 \\
\hline Q3 $(0.40$ to $<0.71)$ & 160 & 485 & 1.932 & $1.288-2.898$ & .001 & 1.496 & $0.963-2.325$ & .07 \\
\hline 1 (ref) & 49 & 235 & 1.000 & - & - & 1.000 & - & - \\
\hline
\end{tabular}


both individual factors, including age and time period of last general practitioner visit, and system-level factors (as we matched on general practitioner practice), thereby controlling for general practitioner staff composition, deprivation level, and alternative service availability such as out-of-hours care. By controlling for system-level factors, we eliminated the effect of local alternative primary care facilities.

\section{Comparison With Existing Literature}

Most previous UK studies of continuity have been ecological in nature, involving aggregated data at the practice level, ${ }_{11-15}$ meaning that associations cannot necessarily be applied to individual patients. The study of Barker et $\mathrm{a}^{10}$ was one of the first in the United Kingdom to link continuity of care and number of hospital admissions using individual-level data. Our study used individual-level longitudinal data, allowing a stronger basis for inferring a causal relationship between continuity of care and first emergency hospital admission between April 2012 and March 2014. Other recent individual-based studies investigating the relationship between continuity of care and hospitalization have come from Taiwan ${ }^{5.7}$ and have shown similar findings, although that country's health care system is not completely comparable: Taiwan implemented compulsory health insurance in 1995 and has a health care system with less focus on the gatekeeper role of general practitioners. ${ }^{35}$ These studies used measures of continuity of care similar to those we used, but excluded patients with only a few general practitioner consultations, which could introduce bias; additionally, 2 of the studies focused on diabetic patients alone. Furthermore, the outcomes in the Taiwanese studies included emergency department visits, avoidable hospitalizations, and hospital admissions in general. Those differences might limit comparability of their findings with ours, although they show the value of our work for the United Kingdom and considerations for future research.

\section{Implications for General Practices and Future Research}

We have assumed that avoiding hospitalization is beneficial, consistent with results from the Dutch cohort study ${ }^{36}$ As our study shows, older adults who experienced marked discontinuity of care had an increased risk of emergency hospital admission. This finding might be highly relevant for policy makers because of increasing size of elderly populations. ${ }^{37}$ Discontinuity of care reduces the opportunity for building trust and mutual responsibility between patients and physicians, which might underlie the increased risk of emergency hospital admission. ${ }^{37}$ More qualitative and quantitative research is needed, therefore, to understand the relationship between continuity of care and reasons for admission, and to understand patients' values and experiences of continuity of care. ${ }^{38}$ Distinguishing between general practitioner-referred emergency hospital admissions and admissions through an emergency department requires a larger data set. Qualitative research might help us understand how, when, and why continuity of care influences health care use, shedding light on factors such as consultation skills of the general practitioner, physician knowledge of patients, patient trust in the physician and his/her abilities, and patient feelings of loyalty toward the physician. ${ }^{39-41}$ The introduction in 2014 of a "named general practitioner" who is responsible for the health care for each patient aged 75 and older offers the opportunity to investigate whether this intervention indeed has resulted in better longitudinal continuity of care and in reduced hospital admission. ${ }^{42}$

To read or post commentaries in response to this article, see it online at http://www.AnnFamMed.org/content/15/6/515.

Submitted December 15, 2016; submitted, revised, May 11, 2017; accepted June 5, 2017.

Key words: continuity of care; primary care; emergency hospital admission; longitudinal data; family practice; practice-based research

Funding support: This work was funded by the National Institute for Health Research School of Primary Care Research (NIHR SPCR), grant funded round 9, principal investigator R.W.M., project number 246. D.L. is funded by the NIHR Oxford Biomedical Research Centre.

Disclaimer: Views and opinions expressed herein represent those of the authors, not the funding bodies.

Previous presentations: This research was previously presented at the Lancet Public Health Science conference, Cardiff, United Kingdom, November 25, 2016, and at the 45th annual scientific meeting of the Society for Academic Primary Care, Dublin, Ireland, July 6-8, 2016.

Supplementary materials: Available at http://www.AnnFamMed. org/content/15/6/515/suppl/DC1.

\section{References}

1. Thompson MI, Lasserson D, McCann L, Thompson M, Heneghan C, Lambert E. Suitability of emergency department attenders to be assessed in primary care: survey of general practitioner agreement in a random sample of triage records analysed in a service evaluation project. BMJ Open. 2013;3(12):e003612.

2. Penson R, Coleman P, Mason S, Nicholl J. Why do patients with minor or moderate conditions that could be managed in other settings attend the emergency department? Emerg Med J. 2011;29(6):487-491.

3. van Walraven C, Oake N, Jennings A, Forster AJ. The association between continuity of care and outcomes: a systematic and critical review. J Eval Clin Pract. 2010;16(5):947-956.

4. Huntley A, Lasserson D, Wye L, et al. Which features of primary care affect unscheduled secondary care use? A systematic review. BMJ Open. 2014;4(5):e004746.

5. Cheng S-H, Chen C-C, Hou Y-F. A longitudinal examination of continuity of care and avoidable hospitalization: evidence from a universal coverage health care system. Arch Intern Med. 2010;170(18): 1671-1677. 
6. Lin W, Huang I-C, Wang S-L, Yang M-C, Yaung C-L. Continuity of diabetes care is associated with avoidable hospitalizations: evidence from Taiwan's National Health Insurance scheme. Int J Qual Health Care. 2010;22(1):3-8.

7. Tsai H-Y, Chou Y-J, Pu C. Continuity of care trajectories and emergency room use among patients with diabetes. Int J Public Health. 2015;60(4):505-513.

8. Salisbury C, Johnson L, Purdy S, Valderas JM, Montgomery AA. Epidemiology and impact of multimorbidity in primary care: a retrospective cohort study. Br J Gen Pract. 2011;61(582):e12-e21.

9. Ridd MJ, Ferreira DLS, Montgomery AA, Salisbury C, Hamilton W. Patient-doctor continuity and diagnosis of cancer: electronic medical records study in general practice. Br J Gen Pract. 2015;65(634): e305-e311.

10. Barker I, Steventon A, Deeny S. Association between continuity of care in general practice and hospital admissions for ambulatory care sensitive conditions: cross-sectional study of routinely collected, person-level data. BMJ. 2017;356:j84.

11. Bankart MJ, Baker R, Rashid A, et al. Characteristics of general practices associated with emergency admission rates to hospital: a cross-sectional study. Emerg Med J. 2011;28(7):558-563.

12. Soljak M, Calderon-Larrañaga A, Sharma $P$, et al. Does higher quality primary health care reduce stroke admissions? A national crosssectional study. Br J Gen Pract. 2011;61(593):e801-e807.

13. Gunther S, Taub N, Rogers S, Baker R. What aspects of primary care predict emergency admission rates? A cross sectional study. BMC Health Serv Res. 2013;13(1):11.

14. Wiseman CE, Baker R. Exploration of population and practice characteristics explaining differences between practices in the proportion of hospital admissions that are emergencies. BMC Fam Pract. 2014;15(1):101.

15. Tammes P, Morris RW, Brangan E, et al. Exploring the relationship between general practice characteristics, and attendance at walk-in centres, minor injuries units and EDs in England 2012/2013: a crosssectional study. Emerg Med J. 2016;33(10):702-708.

16. Rowlands S, Moser K. Consultation rates from the general practice research database. Br J Gen Pract. 2002;52(481):658-660.

17. Blunt I, Bardsley M, Dixon J. Trends in Emergency Admissions in England 2004-2009: Is Greater Efficiency Breeding Inefficiency? London, England: Nuffield Trust; 2010.

18. Herrett E, Gallagher AM, Bhaskaran K, et al. Data Resource Profile: Clinical Practice Research Datalink (CPRD). Int J Epidemiol. 2015; 44(3):827-836.

19. Williams T, van Staa T, Puri S, Eaton S. Recent advances in the utility and use of the General Practice Research Database as an example of a UK Primary Care Data resource. Ther Adv Drug Saf. 2012;3(2):89-99.

20. Menec VH, Sirski M, Attawar D, Katz A. Does continuity of care with a family physician reduce hospitalizations among older adults? J Health Serv Res Policy. 2006;11(4):196-201.

21. Salisbury C, Sampson F, Ridd M, Montgomery AA. How should continuity of care in primary health care be assessed? Br J Gen Pract. 2009;59(561):e134-e141.

22. Saultz JW. Defining and measuring interpersonal continuity of care. Ann Fam Med. 2003;1(3):134-143.

23. Bice TW, Boxerman SB. A quantitative measure of continuity of care. Med Care. 1977;15(4):347-349.

24. Bentler SE, Morgan RO, Virnig BA, Wolinsky FD. The association of longitudinal and interpersonal continuity of care with emergency department use, hospitalization, and mortality among Medicare beneficiaries. PLoS One. 2014;9(12):e115088.
25. Starfield BH, Simborg DW, Horn SD, Yourtee SA. Continuity and coordination in primary care: their achievement and utility. Med Care. 1976;14(7):625-636.

26. Hippisley-Cox J, Coupland C. Predicting risk of emergency admission to hospital using primary care data: derivation and validation of QAdmissions score. BMJ Open. 2013;3(8):e003482.

27. Springate DA, Kontopantelis E, Ashcroft DM, et al. ClinicalCodes: an online clinical codes repository to improve the validity and reproducibility of research using electronic medical records. PLoS One. 2014;9(6):e99825.

28. Reilly S, Olier I, Planner C, et al. Inequalities in physical comorbidity: a longitudinal comparative cohort study of people with severe mental illness in the UK. BMJ Open. 2015;5(12):e009010.

29. Doran T, Kontopantelis E, Valderas JM, et al. Effect of financial incentives on incentivised and non-incentivised clinical activities: longitudinal analysis of data from the UK Quality and Outcomes Framework. BMJ. 2011;342:d3590.

30. Reeves D, Springate DA, Ashcroft DM, et al. Can analyses of electronic patient records be independently and externally validated? The effect of statins on the mortality of patients with ischaemic heart disease: a cohort study with nested case-control analysis. BMJ Open. 2014;4(4):e004952.

31. Kontopantelis E, Springate D, Reeves D, Ashcroft DM, Valderas JM, Doran T. Withdrawing performance indicators: retrospective analysis of general practice performance under UK Quality and Outcomes Framework. BMJ. 2014;348:g330.

32. Carr MJ, Ashcroft DM, Kontopantelis E, et al. Clinical management following self-harm in a UK-wide primary care cohort. J Affect Disord. 2016;197:182-188.

33. Kristjansson E, Hogg W, Dahrouge S, Tuna M, Mayo-Bruinsma L, Gebremichael G. Predictors of relational continuity in primary care: patient, provider and practice factors. BMC Fam Pract. 2013;14(1):72.

34. Worrall G, Knight J. Continuity of care for older patients in family practice: how important is it? Can Fam Physician. 2006;52(6):754-755.

35. Wu T-Y, Majeed A, Kuo KN. An overview of the healthcare system in Taiwan. London J Prim Care (Abingdon). 2010;3(2):115-119.

36. Maarsingh OR, Henry Y, van de Ven PM, Deeg DJ. Continuity of care in primary care and association with survival in older people: a 17-year prospective cohort study. Br J Gen Pract. 2016;66(649): e531-e539.

37. Tammes P, Salisbury C. Continuity of primary care matters and should be protected. BMJ. 2017;356:j373.

38. Boulton M, Tarrant C, Windridge $K$, Baker R, Freeman GK. How are different types of continuity achieved? A mixed methods longitudinal study. Br J Gen Pract. 2006;56(531):749-755.

39. Merriel SWD, Salisbury C, Metcalfe C, Ridd M. Depth of the patient-doctor relationship and content of general practice consultations: cross-sectional study. Br J Gen Pract. 2015;65(637):e545-e551.

40. Noble LM. The future of the doctor-patient relationship. In: Brown JN, Lorraine M, Papageorgiou A, Kidd J, eds. Clinical Communication in Medicine. Oxford, UK: John Wiley \& Sons, Ltd.; 2015:57-64.

41. Ridd M, Shaw A, Salisbury C. 'Two sides of the coin'-the value of personal continuity to GPs: a qualitative interview study. Fam Pract. 2006;23(4):461-468.

42. Lloyd T, Steventon A. Effect of Named, Accountable GPs on Continuity of Care: Protocol for a Regression Discontinuity Study of a National Policy Change. Int J Integr Care. 2016;16(1):6. 